\title{
O debate sobre a regulamentação do ato médico no Brasil
}

\author{
The debate about the regulation \\ of the medical act in Brazil
}

Regina Guedes Moreira Guimarães 1

Sérgio Rego 2

\footnotetext{
1 Departamento de Saúde da Comunidade, IB/CCBS Un iversidade Federal do Estado do Rio de Janeiro, Unirio.

Rua frei Ca n eca 94, Cen tro, 20211-040, Rio de Janei ro RJ. rgguima@hotmail.com

2 Escola Nacional de Saúde Pública Sergio Arouca,

Fiocruz.
}

Abstract This article discusses the demand for the regulation of the "medical act" in Brazil considering the theoretical framework adopted by the sociology of the professions. It presents and analyzes the main arguments of the health corporations based in official documents and main actors' interviews. The process is understood as a legitimateaction of defense of the preroga tives and corpora te privileges. Recognizing that the dispute is related to the construction of the professional identities it defends that the regulation of the health professions must respect their competences and theoretical and practical abilities. It concludes emphasizing that the role of the State in the regulation of the professions must consider the in terests of the society in face of the intense technical division of the work that happened in the health sector. This means to respect the exdusive competences of the medicine and recognize those of the new professions of the area, such as physiotherapy, phonoaudiology, psychology and others.

Key words Sociology of the professions, Professional identities, Health professions
Resumo Este artigo discute a demanda pela regulamentação do "a to médico" no Brasil à luz do referencial teórico da Sociologia das profissões. Apresenta e analisa os principais argumentos trazidos pelas co rporações ao deba te político a partir de documentos oficiais e entrevistas dos principais atores, en tendendo o processo como legítima busca de defesa das prerrogativas e privilégios corporativos. Reconhecendo que a disputa está relacionada à construção das iden tidades profissionais, defende a regulamentação das profissões da á rea da saúde respeitando-se suas competências e habilidades teóricas e práticas. Conclui enfatizando que o papel do Estado na regulamentação das profissões precisa considerar os interesses da sociedade diante da intensa divisão do trabalho ocorrida na área da saúde, respeitando-se as competências exdusivas da medicina e reconhecendo as das novas profissões da área, como fisioterapia, fonoaudiologia, psicologia e outras.

Palavras-chave Sociologia das profissões, Identidade profissional, Profissões de saúde 
As modernas sociedades ocidentais se desenvo lveram com a idéia de que profissional é um indivíduo possuidorde um saber e de um fazer que não apenas resolve problemas concretos relacionados com o cotidiano de seus membros, como também o faz defendendo primariamente os interesses de seus clientes. Desta forma, em troca da afirmação desses interesses primários, a sociedade, por intermédio do Estado, con fere a esses grupamentos profissionais a exclu s ivi d ade da pr á tica em determinadas atividades e delega às corporações a autoridade para se auto-regulamentar. O poder de autoregulamentação é uma das maiores ambições dos grupos ocupacionais, até por pressupor a capacidade de definir os seus próprios limites profissionais e, por conseguinte, a delimitação do campo profissional.

Não é por outra razão que se pode verificar nos materiais promocionais dos organismos profissionais um reflexo da competição entre categorias profissionais: "Fisioterapia com fisiotera peuta", "Administração com administradores", "Não construa sem con sultar um arquiteto" e "Não assine nada sem consultar um advogado", refl exo de suas disputas com médicos fisiatras e engen h ei ros civis e de afirmação da relevância social de suas com petências específicas.

O desejo de se auto - regulamentar também e s teve ex presso nos recen tes embates no campo do jornalismo: desde a luta pela exigência do diploma universitário para o exercício à tentativa (até agora malsu cedida) de criar um órgão de regis tro e con trole do exercício profissional existente nas demais profissões de nível superior. Esse debate não tem uma relação mais profunda com a discussão sobre a "liberd ade de in formação", mas sobre como se dão (ou se darão ou dariam) as relações entre capital e trabalho neste início de século 21 neste campo.

Como veremos ao final de ste artigo, defendemos a idéia de que um dos panos de fundo dessas discussões atuais sobre profissões é o ataque, pelos representantes do capital, às profissões em geral e às or ganizações profissionais em particular. A derrota da proposta do socialismo real e a atual hegem onia do chamado neoliberalismo marcam um declínio da capacidade de intervenção e de luta das organizações dos trabalhadores. O que hoje se configura politicamentemais atuante (embora de efetividade ainda pou co eviden te) é o movim en to antiglobalização, cujos atores mais releva n tes estão reu ni dos em or ganizações não-govern a mentais e não em organizações típicas de trabalhadores.
No caso do campo da saúde, enten demos que está ocorren do um processo de "repactuação" l egal, como um resultado da intensa divisão do trabalho que aí ocorreu. Este não seria um fenômeno apenas brasileiro, mas que também é ob s ervado, por exemplo, nos Estados Unidos, como demonstra o artigo de Fink (1997). A novid ade estaria no enfraquecimento das organizações corpora tivas, enfraquecimen to que é favorec i do com a fragmentação das profissões.

No Brasil, uma consulta na página da Câmara Federal, na Internet, aponta a existência de 86 projetos de lei em tramitação, que tratam da regulamentação do exercício de profissões, sendo que 24 projetos são considerados inativos. Entre esses proj etos, está sen do proposta a concessão do poder de auto - regulamentação (expressa pela proposta de criação de Conselhos Federal e Estaduais) a 12 corporações de profissionais: a) com formação em curso superior: os profissionais de Educação Física, analistas de sistemas, turismólogos, psicomotricistas, músicos e psicopedagogos; b) sem formação em curso su perior: técnicos agrícolas, instrumentadores cirúrgicos, despachantes, árbitros de futebol, professores de ioga e técnicos de seg u rança de trabalho.

As disputas, entretanto, não se dão apenas en tre as corporações. É cl a ro que qu a n do a corporação A ou B defen de seu mon opólio de prática ela está, de fato, defen den do um monopólio econômico sobre uma prática. Embora o panorama aqui apres entado sugira que o merc ado de trabalho seja fortemente relacionado com as profissões, existem sinais de que o mu ndo profissional está em crise. Aqui no Brasil, por exemplo, Mach ado (1996) discutiu amplamen te esta crise e as tra $\mathrm{n}$ s formações relacionadas com o status profissional das ocupações na saúde, em particular os médicos, em decorrência de mudanças na forma de inserção no merc ado de trabalho (incluindo o assalariamento), dimi nuição rela tiva da auton omia profissional, aumento da procura pelas instâncias judiciais comuns para resolver as contendas entre profis sionais ed i entes, etc.

Assim, é neste con tex to de intensa luta pela delimitação dos campos de prática exclusiva das profissões e de "repactuação" desses campos de competência com a socied ade que procuraremos discutir os recen tes embates en tre a corporação médica e as demais corporações da área da saúde em torno da delimitação do cham ado "a to médico". Esta "rep actuação" tornouse indispen sá vel pela atual complexidade da di- 
visão hori zontal e vertical do trabalho (social e técnica) no campo da saúde, associada com as mudanças decorren tes da cre s cen te incorporação de recursos de alta tecnologia no campo, redefinindo o escopo de atuação dos diversos a tores em questão. Nossa proposta neste artigo é a de buscar entender os movimentos que as corporações estão fazendo à luz da sociologia das profissões, tendo como eixo temático a construção da iden tidade profissional.

\section{Profissão e profissionalização}

O tipo de ocupação que mais freqü en temen teé ch a mada em estu dos sociológi cos de profissão é uma ocupação de tem po integral, que está estreitamente ligada à criação de escolas de treinamento, de associação profissional, de autoregulamentação e de adoção de um código de ética. Uma profissão, p a ra ser considerada como tal, precisa, ao lon go do tempo, consolidar um corpo esotéri co de con hecim en toe ser orien tada para um ideal de serviços, is toé, servir primariam en teaos interesses da comu nidade ( Machado, 1995).

SegundoGoode (1969):

1) Idealmente, o conhecimento e habilidades devem ser abstra tos e organizados em um corpo codificad de princípios;

2) O conhecimen to deve ser aplicável, (...), a probl emas con c retos da vida;

3) A sociedade ou seus membros mais relevantes devem acreditar que o conhecimento pode, atualmente, re solvê-los (...);

4) Membros da soc i ed ade devem também aceitar como adequado que esses problemas não sejam mais encaminhados para outros grupos ocupacionais, já que este grupo ocupacional é que detém ocon hecimen to e não os outros;

5) A própria profissão deve ajudar a criar, organizar e transmitir ocon hecimen to;

6) A profissão deve ser aceita como árbi tro final em qualquer disputa sobre a validade de qualquer solução técnica envolvendo área de sua su posta competên cia;

7) A quantidade do conhecimen to e habilidades e a dificuldade em ad quiri-los devem ser tão gran des que os membros da sociedade vejam a profissão como possuindoum certo grau de mistério que não é acessível aos hom ens comuns por seus próprios esforços ou mesmo sem ajuda.

Os estudos sobre como uma ativid ade ocup acional adqui riu status de profissão nas socie$\mathrm{d}$ ades modernas deram um determinado dese- nho ao processo de profissionalização, ca racterizado pela estruturação de privilégios profi ssionais, que depois foram questionados pelas profissões que se seguiram, quan do da sua luta corporativa. Nesse processo, as universidades representaram uma instância jurídico-legal, onde se transmite o conhecimen to formal, o corpo esotérico de conhecimen to.

Para Wilensky (1970), a profissionalização de uma ocupação se dá por meio de um processo de oi to etapas que inclui: a ocupação torn a r-se uma atividade de tem po integral; a criação de um sistema de ensino formal com a distinção en tre os que estão mais dedicados à prática ou ao ensinoprofissional; a criação de uma associação profissional nacional; in tensa disputa política interna con tra os que se dedicam à ocupação há mais tempo (que resistem à atualização do trabalho); e externa (contra as ocupações com atividades semelhantes); e a criação de um código de ética para reduzir a competição interna e para proteger os clientes e enfatizar o ideal de serviço. Com a redefinição das t a refas de sua com petência, o trabalho menos qualificado fica del egado a subordinados.

Assim, como nas demais soci i ed ades ocidentais e também no Brasil, as profissões reconhecidas como as mais anti gas são a medicina e a advocacia e seus processos de profissionalização são model a res para as demaisocupações. Santos (1995) descreveu o processo de profissionalização da medicina no Brasil e é correto afirmar que, em bora mais lentamente, ele tenha acompanhado o processo de industrialização. Som ente a partir da década de 1930, é que ele se acel era, ten do, também, a diversificação do merc ado de trabalho, como uma das conseqüências. Este fenômeno é facilmente compreendido, dada a estrita relação en tre o de senvo lvi m en toecon ômi coe o aumen to de sua complexidade e o desenvolvimen to das formas como as ocupações se or ganizam na inserção no merc ado.

Muitas oupações, que surgiram a partir da divisão do trabalho, têm bu scado sua profissionalização na formação de nível superior. Isso ocorreu de tal modo que, por exemplo, no campo da saúde o Con selho Naci onal de Saúde (CNS, 2004) reconheceu, em 1997, os 13 profissionais de saúde de nível superi or, a saber: os assisten tes sociais, os biólogos, os profissionais de Educação Física, os en fermeiros, os farmacêuticos, os fisioterapeutas, os fonoaudiólogos, os médicos, os médicos veterinários, os nutricionistas, os odon tólogos, os psicólogos e os tera peutas ocupacionais. Com referência aos as- 
sistentes sociais, biólogos e médicos veterinários, a caracterização como profissionais de saúde deve ater-se a dispositivos legais do Ministério da Educação, do Ministério do Trabalho e dos Conselhos de Classe dessas categorias.

Noentanto, a expansão das escolas su periores de formação profis si onal não ocorreu como expressão de uma política articulada para os s etores educacional e profissional, que pudesse respon der adequadamente à relação entre o contingen te de formados e o mercado, e sua distribuição no país. Es te de s compasso implicou o aumen to da con corrência no mercado de trabalho nos centros urbanos, contribuindo para o ach a ta men to salarial, em er gin do o profissional assalariado, até mesmo em profissões tradicionais como a medicina (Ma rinho, 1986). Dentre os possíveis resultados desta [falta de] política, associada com a intensa divisão do trabalho, estão a redução dos salários e o aumento das disputas entre profissionais pelo campode prática.

Não desejamos parecer estar apregoando o fim do assalariamento profissional ou especulando sobre como a vida seria se não fosse do jei to que é. Q u eremos de st acar que a oferta excessiva de força de trabalho qualificada na área da saúde levou, necessariamente, à diminuição dos rendimentos, particularmen te em países como o Brasil, on de o Estado tem uma grande importância como em pregador. Embora constitucionalmentea saúde seja uma obrigação do Estado, esta obri gação não reperc ute no oferecimen to de remu neração salarial coeren te com a importância da retó rica discurs iva. Trabalhadores de outros or ganismos de Estado têm uma remun eração muitas vezes superior a dos trabalh adores mais qualificados na área da saúde.

Particularmente, a ampla oferta de profissi onais de saúde assegurou, sim, uma diminu ição proporcional nos salários oferecidos. Mesmo para os médicos, que sem pre foram o componen te com maior prestígio social e o mais nu meroso da força de trabalho qualificada. Este parece ser um segun do degrau na deteri oração da relação en tre médicos e o Estado. O primei ro seria a aprovação, no início da década de 1960, da possibilidade de os médicos terem duas matrículas - dois vínculos - com o Estado, em vez de terem obtido um aumen to salarial, (mas esta é outra história).

Se, durante as décadas de 1970 e 1980 , era comum a denúncia do modelo de assistência à saúde (criado em nosso país, baseado na presença do médico e do aten dente de enferma- gem e enfoc ado, também, na luta pelo reconhecimen to da importância dos saberes profissionais das demais profissões de saúde), o gran de crescimento do número de faculdades para graduação de outros profi ssi onais de saúde, especialmentenas décadas de 1980 e de 1990, fez com que sua pres ença nas equipes se ampliasse sobremaneira (Machado et al., 1990).

Nesta época, as grandes mudanças ocorridas na or ganização do sistema (com a transferência da assistência médica para o âmbi to do Ministério da Saúde, a criação do Si s tema Unifi cadoDescen tralizado de Saúde e a doSis tema Único de Saúde) também ocorreram em relação às políticas de recursos humanos setoriais. Destas, ainda pou co se discute sobre a imple$m$ entação da isonomia salarial por nível de escolaridade. A implementação desta política desconsiderou o princípio de que a composição do valor da remuneração salarial é direta$m$ en te relacionada com o custo de reprodução daquela força de trabalho. Logo, qu an to maior a especialização, quanto maior o tempo de formação, maior deveria ser a remuneração.

Um fenômeno que pode ser considerado uma possível con s eqüência de s te processo foi o afastamentoda maioria dos médicos dos serviços assistenciais públicos de saúde, uma vez que estes profissionais contavam com alternativas que traziam maior recom pensa financeira às suas atividades. Esta afirmação, entretanto, não significa que ignoremos ou minimizemos a complexidade dessa questão ou o papel desempen hado pela crise de financiamen to do setor, mas sim o nosso desejo de destacar um fator muito pouco considerado e que julgamos estratégi co na compreensão do fen ô meno e do papel que os profissionais vão desempenhar a partir de então.

Em seguida ao início dos anos 90, observou-se um gran de con tin gen te de profissionais mudar sua concepção sobre em pregos na rede pública de saúde: de um em prego desejado pela maioria dos médicos até o final da década de 1980 , passou a ser encarado como um em prego temporário, pronto para ser descartado logo que uma nova e mel hor alternativa de remu eração su rgisse. Alguns especialistas, como anestesistas, neu rocirurgiões e ortopedistas, buscaram o caminho do afastamen to do sistema como empregados, optando pela venda de seus serviços, em uma alternativa bem mais lucrativa. Isso foi tão eficaz que os anestesistas a esten deram para os serviços privados do sistema de pré-pagamento. 
Se a relação desses profissionais com o setor públ i co se deteri orou a tal pon to, em parte pela multiplicação da oferta, a relação com o setor privado não pareceu melhor: do vínculo como profissional autônomo (que apenas aparentemen te pre servava sua condição "liberal"), passou para o vínculo de profissional credenciado (seja com as empresas de pré-pagamento, seja com o próprio setor público) e para o de empregado direto, até chegar à desperson alização, na qual o indiví duo deixa de ser pessoa física e passa a ser pessoa jurídica, transform a ndo-se em umaempresa.

No Brasil, pa ra as empresas de assistência à saúde privadas, baseadas no pré-pagamento, corporações de profissionais fortes significam dificuldades maiores nas negociações das remu n erações. Fa to que fica evi den te para qu em acompanha as negociações entre as organizações representativas dos médicos com essas empresas na implantação de uma tabela de remu neração profissional.

Com o objetivo de reduzir custos, a forma de pagamen to dos serviços vem sendo francamen te question ada e já estão sen do testadas altern a tivas há bem mais de uma década nos EUA. Referimo-nos aos Diagno stic rel a ted group s. um sistema para categorizar pacien tes, baseado em seus diagnósticos primários e secundários, procedimentos primários e secundários, idade e du ração da internação. É, então, determinado um custo uniforme para cada categoria (Pittsburg State University, 2005). Salienta-se que, neste processo, desaparecem da remuneração os trabalhos específicos das diversas corporações profissionais, in cluídos na condição genérica da assistência. Se por um lado este proce sso é positivo, dando ênfase à assistência global do paciente, por outra, enfraquece sobremaneira a capacidade das corporações defenderem seus ganhos salariais e, definitivamente, perde-se de vista boa parte da identidade profissional dos envo lvidos.

Se, an tes da intensa divisão de trabalho na saúde, a auto - regulação profissional era suficien te para dirimir dúvidas sobre os campos profissionais, hoje, o recorrer à justiça é a regra, criando-se assim a demanda por legislações específicas sobre os temas. Assim, para afi rmar seu campo de atuação, delimitando-o ou ampliando-o, as corporações profissionais precisam sensibilizar diferentes segmentos da sociedade e, s obretu do, estruturar argumentos consistentes que embasema defesa para os projetos de lei que pleiteiam (um deles, a regula- mentação de suas profissões) ou argumentos que impeçam a aprovação de leis que contrari em os interesses corpora tivos.

Como exemplo, a definição em lei dos ato s profissionais das diferentes categorias tem representado, nos últimos trinta anos, no Brasil, uma das frentes de luta pelo mon opólio prof i ssional. En ten demos ato profissional como uma ação que a legislação regulamentadora de uma profissão atribui aos agentes de uma categoria profissional, seja ele exclusivo ou compartilhado com outras profissões e que deva ser realizado por pessoa habilitada, no exercício legal de sua profissão. A definição jurídica do ato profissional é um dos aspectos que consolida a identidade profissional, que é, por sua vez, socialmen te construída, ao lon go de um período histórico suficien te para determinar que seus elemen tos constitutivos se incluam na consciência social.

No entanto, a consideração do ato profissional no âmbito jurídico é uma inflexão recen te no processo de discussão das competências profissionais, já que, antes, apenas a formação bastava para distinguir seus saberes respectivos. Com isso, a disputa pelo monopólio da prática da medicina ficou mais evidente com a intensa divisão do trabalho nas sociedades modernas e com o surgimento de novas ocupações nesse campo de conhecimen to. Foi nesse contex to que surgiu a necessidade sentida pela categoria médica de regulamentar o ato médico.

\section{O projeto de lei sobre o ato médico e as disputas profissionais}

O debate sobre a necessidade de regulamentação do ato médico tem o seu marco em 1989, quando o deputado federal Pedro Cañedo a presenta um proj eto de lei que atri buía ao Conselho Federal de Medicina (CFM) a definição do ato médico. Não haven do, porém, apoio da entidade, o proj eto foi reti rado por seu autor. $\mathrm{Ou}$ tras iniciativas, no âmbi to do CFM, foram fru stradas e a discussão conti nuou nos Conselhos Regionais, nos anos seguintes, ten do à fren te o Rio de Jan ei roe Santa Cata rina (Cremerj, 1998).

As discussões se segu i ram até que, em março de 1998, o Conselho Regi onal de Medicina do Estado do Rio de Jan ei ro (Crem erj) definiu o ato médico, com a re so lução no. 121/98, enum erando critérios e exigências para o exercício da profissão médica. Diz no Art. 1:: Ato médico 
é a ação desenvolvida visando à prevenção, ao diagnóstico, tratamento e à reabilitação das alterações que possam comprometer a saúde física e psíquica do ser humano (Cremerj, 1998).

Em seguida, o CFM, em 18 de dezembro de 1998, aprova o novo Estatuto para os Conselhos de Medicina. O Art. 1o diz: O Co n selho Federal de Medicina e os Conselhos Regionais de Med icina são órgãos supervisores, normatizadores, disciplinadores, fiscalizadores e julga do res da atividade profissional médica em todo o território nacional. $\mathrm{E}$, como consta no Art. 30 , inciso IX, é a ele atribuído "definir e norm a tizar o ato médico" (CFM, fev./1999).

Por conseguinte, em outubro de 2001, o CFM cria a resolução 1.627/2001, que define o a to profissional de médico como todo o procedimento técnico-profissional praticado por médico legalmen te habilitado e dirigido para a prevenção primária, secundária e terciária. Esta re s o lução refere, também, que as ativi d ades que envolvam procedimentos diagnósticos de enfermidades ou impliqu em indicação terapêutica são priva tivas dos médico $s$, sen do que as outra $s$ atividades podem ser atos profissionais compartilhados com outros profissionais da área de saúde, den tro dos limites impo s tos pela legislação pertinente, excluin do o exercício da odonto logia, nos termos da lei. Estabeleceram-se, a ssim, as bases que con struíram, po steriormente, o Projeto de Lei do Ato Médico PLS 025/02.

Os esforços da categoria médica não foram suficien tes para fazer avançar o referi do proj eto no Con gresso Nacional. Dessa forma, a Comissão Nacional em Defesa do Ato Médico, constituída por representantes de suas diversas organizações, passa a trabalhar em várias estratégias. Por exemplo, em outubro de 2003, o CFM distribu iu ao Congresso Nacional o projeto de lei no 25, de 2002 - PLS 025/02, na forma de cartilha, divulgando-a amplamente em o utros espaços, sustentan do que a definição do campo de trabalho é uma necessid ade elem entar na institucionalização de uma profissão e estabelecendo uma identidade médica legalmente instituída que assegure sua atividade profissional e o melhor atendimento ao indivíduo e à col etivid ade (CFM, 2003). Mas do que trata o Projeto propria mente dito?

A resolução do CFM, que deu origem ao Proj eto, era curta e objetiva: definia como ato privativo do médico toda e qualquer atividade que envolvesse a execução "de procedimentos diagnósticos e terapêutico s", ressalvadas aquelas praticadas pela odontologia, que eram ex- cluídas da definição, no seu artigo segundo. Dessa forma, em uma resolução de seu órgão auto-regulamentador, subordinar-se-iam à profissão médica todas as demais profissões de saúde e seria ved ado que qu a l qu er outro profissional pudesse fazer diagnóstico ou alguma ação terapêutica. Parece daro que o modelo depreendido dessa proposta regulamentadora era o modelo que considerava as demais profissões de saúde atividades paramédicas, em um estágio pré-profissional, ou seja, de apoio ou suporte à medicina.

Já, o projeto substitutivo do senador Tião Viana (2002), embora con tenha o mesmo nú$m$ ero de artigos (cinco), consegue ser mais genéri co. $O$ parágra fo único do artigo primei ro dispõe que são atos privativos de médico a formulação do diagnósti co médico e a pre scrição terapêutica das doenças, respeitado o livre ex ercício das profissões de saúde nos termos de suas legislações específicas. Assim, o sen ador cons egue propor algo que não re s o lverá os con fli tos existen tes en tre as profissões, pois se exime de def $\mathrm{i}$ nir o que seria diagnósti co médico em con traposição, por exemplo, ao diagnóstico fonoaudiológico ou fisioterapêutico. O proj eto substitutivo aparen temente deixa aberta a porta para que cada profissão tenha seu exercício re s pei t ado "nos termos de sua legislação específica". Mas, essa não parece ser a interpretação da mai oria dos opositores do proj eto. Por que, então, a polêmica persiste?

As demais categorias profissionais da saúde se têm posicionado con trariamen te ao proj eto de lei para definição do ato médico, refutandoo contunden tem ente. Pa ra alguns, o proj eto de lei é considerado um retrocesso no campo da saúde, ao preten der cen tralizar na mão dos médi cos todas as atividades rel a tivas ao diagnóstico de enfermidade e ao tratamen to da saúde, excluin do os avanços na relação interdisciplinar de profissionais de várias áreas que podem conjunta e coletivamente atuar e se responsabilizar pelo trabalho de tratamento, prevenção e promoção da saúde (Redepsi, 2003).

Ricardo Moretzsohn, presiden te do Conselho Federal de Psicologia e Coordenador Naci onal da Comissão Contra o Proj eto de Lei do Ato Médico, por exem plo, afirma que "da forma como o projeto se encontra, ele limita ao médico a prescrição tera pêutica" ( Moretzsohn, 2004). Também, tem-se argumentado, con trariamente, que o seu conteúdo apres enta uma $\mathrm{n}$ efasta proposta de restri n gir aos médicos procedimentos já garantidos por lei a outros pro- 
fissionais, ofenden do a Constituição Federal, de 1988, que determina a liberdade de ação profissiomal quando atendidas as qualificações que a lei estabelecer, ferindo a autonomia das profissões de saúde, uma condição básica para $\mathrm{o}$ atendimento integral à saúde do cidadão (Andrade, 2003).

É interessan te notar algumas das áreas nas quais os confli tos são mais evidentes: nutricionistas e nutrólogos e endocrinologistas; fisioterapeutas, médicos fisiatras, profissionais da educação física e médicos especialistas em medicina esportiva; psicólogos, psiquia tras e toda a ampla variedade de psico terapeutas; fon oaudiólogos e otorrinolaringologistas. São áreas em que, de fato, verifica-se um conflito de competências e de limites. Os saberes são, em muitos casos, compartilhados, não fosse a origem comum. Mas por que a disputa com essas novas profissões é tão intensa, mas não o é com a odontologia - que também compartilha o tronco comum das ciências biológicas? Talvez a ú n ica explicação para a falta de conflito no Brasil está no fato de esta separação já se ter dado há mais de um século, mas a questão é essencialmente a mesma.

Na tentativa de identificarmos os pon tos de confli to é intere s s a n tenotar que a en ferm a gem não possui, ao menos de forma evidente, um campo do saber sobre o qual possa reclamar exclusividade. Poderia ser no campo da enfermagem obstétrica (como fica cl a ro na disputa, ora em curso, no Rio de Janeiro), mas não é. A enfermagem parece reclamar uma autorid ade profissional difusa que se confunde com a medicina, em sen ti do mais amplo.

A re s o lução 271/2001, de julho de 2002, do Cofen define que é ação de en ferm a gem (qu a ndo praticada pelo enferm ei ro, como integrante da equipe de saúde) a prescrição de medicamentos, ten do auton omia na escolha e posologia dos mesmos, podendo solicitar exames de ro tina e complementa res no âmbi to de Programas de Sa ú de. Inicialmente, houve a contestação judicial por parte das organizações médicas, com a obtenção de uma liminar para suspender o efei to dessa medida, que foi cassada sob a alegação de que esta prática faz parte de Programas doMinistério da Saúde-o que é fato.

Esta postulação vem en contrando algum grau de respaldo legal, uma vez que é fundamentada na utilização, pelo Ministério da Sa úde, desses profissionais na implantação do Programa de Saúde da Família - PSF, recebendo um treinamento com apostilas que ensinam rotinas simples de tratamen to de doenças freqüen tes e po u cograves, como anemia ferropriva, etc. O probl ema está na utilização de regras gerais, que não são válidas para todos, por profissionais que não estão aptos a realizar o diagnósti co diferencial com problemas mais complexos. A "tecnificação" da assistência à saúde, sua redução à aplicação de regras e ro tinas simplificadas (tão caras aos tempos informatizados dos pro tocolos dínicos, medicina baseada em evidências e inteligência artificial aplicada à medicina), expõe de forma injustificada a população a riscos.

Esta situação está longe de ser definida e ações judiciais seg u emse formando, no âmbi to dos Tribunais Regionais, cujas decisões ainda não criaram juris prudência (CFM, 2004; Cofen, 2005). Resta a pergunta: estariam os en fermei ros de um modo geral capacitados para prescrever medicamentos e solicitar exames complementares no âmbito de Programas de Saú de? Po ssu em formação profi is si onal para tal ou baseiam sua reivindicação em cursos de capacitação genéri cos e even tuais?

O utras vezes a reivindicação dos en ferm eiros se dá em relação às práticas de outras profissões: o Con s elho Federal de Fa rmácias (CFF) questiona a resolução 257/2001, do Cofen, quanto ao prep a ro de drogas quimi o terápicas e antineoplásicas pelo en fermei ro. O CFF alega que este é um ato privativo do farmacêutico. Outro exemplo, é a resolução Cofen - no 295/2004, que dispõe sobre a utilização da técnica do brinquedo/brinquedo terapêutico pelo en fermeiro na assistência à criança hospitalizada, o que poderia ser questionado como prática dos psicoterapeutas, sejam eles psicólogos ou médicos.

Vejamos agora a assistência e educação nutricional a indivíduos sadios ou en fermos, que é considerada uma atividade priva tiva dos nutricionistas, desde a década passada, pela lei 8.234, de 17 de setembro de 1991, que regulamen tou a nutrição. No Art. 4o, incisos VII e VIII, atribuem-se, também, aos nutricionistas as seguintes ativid ades, de s de que rel acionadas com alimentação e nutrição humanas: prescrição de suplemen tos nutricionais, necessários à complementação da dieta e a solicitação de exames laboratoriais necessários ao acompanhamento dietoterápico.

Não há dúvida de que existe um "conflito de fron teira" en tre nutrólogos e nutricionistas, assim como nos parece daro que a tendência é a de ex tinção da especialidade médica, pelo su- 
cesso no recorte do conhecimen to realizado pela nova profissão. Entretanto há que existir uma solução temporária que preserve os interesses e a legitimidade das ativid ades dos médicos que, eventualmente, n ela se dediquem. Outro conflito nesta área localiza-se na pediatria, pelas atividades de puericultura, para as quais também deverão ser estabelecidas soluções conciliatórias que viabilizem, ao menos por um tem po, as práticas de ambos os profissionais.

É importante observar algumas entrevistas con cedidas ao site Universia (2005) por representantes de Conselhos de Profissionais de Saúde que se op õ em ao proj eto de lei em questão. Tiran do o fato de que todos parecem estar se referindo ainda à Resolução do CFM e não ao substitutivo genéri co do sen ador Tião Viana, há um certo consenso em se reconhecer a legitimidade (embora não cheguem a falar de necessidade) da criação de uma lei que regulamen te $o$ ato profis si onal do médico. Jor ge Steinhilber (2005), presi den tedo Con s elho Federal de Educação Física, entretan to, refere-se à necessidade de se criar a lei do ato de cada profissional, para que a socied ade conheça cada uma das profissões e fiquem bem definidas as respectivas competências. Sua posição é bem compreen sível, po s to que estes profissionais estão em permanente atri to profissional com os fisioterapeutas, já que suas ativid ades são, em mu i tos casos, sobrepostas.

Em virtu de dessas considerações, é correto i dentificarmos uma fon te de insatisfações sentidas pelos profissionais de saúde no fato de os atos profissionais se definirem em relação ao ato médico. Insatisfações que são eviden tes e justificáveis, uma vez que os demais profissionais de saúde têm lutado pela construção de sua própria identidade profissional, ao longo de seu processo deprofissionalização, e não desejariam que esta construção se calcasse por oposição ou contraposição com àquela construída pelos médicos.

Já Ricardo Moretzsohn (2004), em bora considere mesmo inaceitável o substitutivo apres ent ado, recon h ece como legítima a regulamentação da profissão médica, mas discorda que esta seja feita por proj eto de lei. Esta afirmação sugere uma tentativa de manter a condição em que cada profissão siga se auto-regulamentando, o que parece improvável, tal a divisão do trabalho no setor, o potencial de conflitos que existe, até mesmo passíveis de recursos jurídicos, cu ja decisão dependerá de interpretações dos juizes em relação a questão.
Ma rinho (1986) já acen tu ava na década de 1980 que a delimitação do controle legítimo sobre determinada esfera do conhecimen to, que garan te à profissão um monopólio e seu domínio de trabalho, é problemática na reali$\mathrm{d}$ ade con creta. O mais comum tem sido a conquista ou garantia de "monopólios de competência", por meio de intensa atividade política que culmina com uma ação regulatória por parte do Estado. É o poder do Estado que garante às profissões o exclusivo direito de usar ou avaliar certo con hecimen to e especialidade. É ele que sanciona e ordena o campo profissional, c ria ou autoriza a criação de cursos universitários, reconhece as diversas associações profissiomis e regulamenta o exercício das profissões. As pectos que se refl etem no curso do trâmite do proj eto de lei 025/02: uma intensa atividadepolítica no sen ti do de que o Estado prom ova ações regulatórias, sancionando e ordenando o campo profissional.

\section{Considerações finais: a necessidade de configuração de um novo modelo no campo das profissões}

Quando uma ocupação consegue se estabel ecer na socied ade, há uma tendência para sua profissionalização. Este processo configura uma iden tid ade profissional, construída ao lon go de um período histórico, representada por um conjun to de elementos cognitivos, norm a tivos e reg uladores socialmen te recon hecidos. Foi assim que as profissões mais antigas, como a medicina e o direi to, em seu processo de profissionalização, de s en h a ramum caminho que outras ocupações também trilharam em busca da conquista das prerrogativas profissionais.

Contudo, no Brasil, com a intensa divisão de trabalho ocorrida especialmente no século 20 , e s te processo de prof i s s i onalização se intensificou, culminando nos anos 90 com um grande número de ocupações pleiteando sua regulamentação profissional ou tentando ampliar o seu escopo de competência e atuação.

Con si derando-se o caso em questão, ainda que desde a década de 1930 o processo de profissionalização de outras profissões de saúde já tivesse se iniciado, a corporação médica em 1957, quando da regulamentação de seu Conselho Federal, não en con trou motivos para definir o ato médico. Nem mesmo no final da década de 1980 , a des pei to do movimen to pela iso- 
nomia salarial, no âmbito do sistema público de saúde, não parecia haver motivos para tal.

$\mathrm{Na}$ realidade, a corporação médica só se preocupou efetivamente com a regulamentação do ato médico, ao final da década de 1990, quando se depara com uma crise refletida em vários âmbi tos do trabalho e da formação médica. Su r ge então a nece s s i d ade cre scen te de defen der o seu mon opólio de competência, ameaçado, por exemplo, pelas reivindicações de privilégios de categorias profissionais que vinham ocupando espaços no setor, amparadas nas legislações de exercício profissional priva tivas ou na possibilidade de demandá-las juridicamente.

Contrapõe-se o fato de que o processo de prof i s s i onalização de outras categorias no campo de trabalho da saúde vem se consolidando, o que tem fortalecido a iden tidade profissional de outras profissões (no âmbito jurídico, ideológico, cultural e político), refor ç ada pelo estabelecimen to de seu corpo de conhecimento, pela normatização de suas ações, pela instituc i onalização do ensino da profissão e pela ocupação de espaços rel evantes, na discussão e solução de problemas de atenção integral à saúde da população.

O utro aspecto que se salienta é que o deb ate atual sobre a regulamentação do ato médico permite construir um desenho do sistema de forças no qual se inserem atualmente as relações profissionais, de svel an do as disputas en tre distintas iden ti d ades profissionais, a busca pela afirmação como profissão e as con tradições e os conflitos de interesses em diversos âmbitos. São estes: na definição de diferentes atos profissionais; na com petição pelo monopólio econômico sobre a prática e pelo monopólio de competências; no poder de auto-regulamentação; na auton omia técnica; no con trole sobre o seu trabalho e o de outros; e nos diversos con stran gim en tos à prática profissional, aí implicados. Mo stra, também, como o aspecto jurídico e as disputas entre as corporações se vinculam e como estão encaminhando o processo históri co das profissões.

Por outro lado, o risco de desestabilização de uma profissão, tão temido numa crise dessa natureza, tem impulsion ado os profis si onais ao diálogo com diversas categorias, agen tes sociais e agências, con du zin do-os à revisão de seus sistemas de referência, a novos questionamentos, a argumen tos e a considerações sobre posicionamentos anteri ores. O reconhecimento da crise é fundamental para a condução do processo de socialização profissional e socialização em geral. Sobretu do, traz a possibilidade de provocar mudanças, a começar pela necessidade de conscien tização acerca das iden ti d ades dos atores que com ela se envolvem e sobre a responsabilidade dos mesmos nesse processo, comprometen do-os com a crítica em relação a seu agir profissional e seu compromisso social maior.

Nas sociedades dem ocráticas - inseridas na atualidade num mu n doglobalizado inform atizado e, sobretudo, com intensa com petição de mercado, estabelecida pela prevalência mundial de uma econ omia neoliberal - ob serva-se, en tre as corporações profissionais, uma intensa luta pelo mon opólio de com petências e limites de atuação. Esta se expressa, por exemplo, nos numerosos projetos de regulamentação de exercício prof is s i onal e no gra ne material divulgado em diversos meios de comunicação, tendo como obj etivo con quistar o apoio dos políticos e da população quanto à rel evância das reivindicações pretendidas.

Tem sido freqü en te, também, que as discussões internas nas corporações e com as demais contrariem a proposta de trabalho em equipe, quando não são consideradas a complexidade da questão e as conseqüências, ao lon go do tempo, das decisões tomadas.

Encaminhando para uma articulação com os aspectos mac roestruturais, vemos que esta disputa tem-se revel ado com um cerne voltado mais para o interesse no mon opólio econômico sobre as prá ticas profissiomis do que para o interesse das corporações profissionais em lutarem por uma participação na con s trução de um projeto social gl obal ou pela implem entação de políticas de saúde (apesar de as corporações centra rem seus discursos, de acordo com seus interesses, s obre a atuação integral à saúde ou ris cos a ela), de trabalho e de formação profissional.

A rigor, o tensionamento do modelo de organização corporativa dos profissionais não é, necessariamente, ruim (nem bom). A regulação das profissões apenas por pares pode gera $\mathrm{r}$ (e com gran de freqüência gera) distorções rel acion adas com a excessiva pro teção dos col egas. A discussão de um novo modelo de organização, que conte mais com representantes não corporativos, parece inevitável e não apenas pela ação do empresariado que atua no campo da saúde. Em nosso país, des de o final da década de 1980, s egm en tos do movimen to sindical apostam na or ganização sindical não corporativa, mas por setor da econ omia (por exemplo, o Sindicatodos Trabalhadores da Saúde). Se is- 
to atenderá também aos interesses da socied ade é uma pergunta para ser ainda respondida.

Portanto, o debate que se tem estabelecido em torno da proposta de regulamentação em lei do ato médico no Brasil traz questões amplas e permite evidenciar uma crise que se reflete no campo das profissões de saúde, indicando a necessidade de discussões mais críticas sobre os modelos atuais de relações profissionais, con siderando sua complexid ade e suas inters ecções macro e micro.

O estudo da organização por profissões, de scolado da rede de relações da qual ele faz parte, não aten de à solução dos probl emas concretos e não con s egue re s pon der primariamente aos interesses sociais mais amplos, dada à incompatibilidade, muitas ve zes existen te, en tre os referenciais e objetivos de projetos sociais defendidos por diferen tes segmentos da soci i ed ade.

No debate em questão neste tex to, apesar de muitos dos representantes das diferentes profissões se preocuparem em incluir em seus argumentos a defesa do SUS e referirem que a aprovação do proj eto de lei inviabilizaria muitas das atividades do SUS, parece que o olhar que ainda falta nesta discussão é aquele que privilegia os interesses da população. Ou, consi dera n do os estágios de desenvo lvim en to moral precon i z ados por Lawren ce Kohlberg, abandonar os argumentos relativos aos estágios egocêntricos, pré-conven ci onais e incorporar pelo menos a pers pectiva do nível conven ci onal que envolve uma preocupação e uma orientação consciente que contribui para o bem-estar da socied ade (Milnitsky-Sapiro, 2000).

Para isso, é indispensável que se faça uma avaliação criteriosa sobre os saberes e competências específicas de cada formação e a pre servação dos limites, respeitada a divisão do trabalho já efetivada, de cada competência. É puro nonsense e perda de tem po das organizações médicas quererem ignorar que outras profissões, de fato e de direi to, se estabeleceram na á rea da saúde. O que se requer agora é o bom s enso críti co de ob servar até aon de vão as possibilidades de autonomia profissional e como todos os profissionais poderão atuar para enfrentar as ameaças de perda de identidade resultantes das novas relações de trabalho e da perda de representatividade e de poder de intervenção das corporações no en frentamen to com as grandes empresas da área da saúde.

\section{Colaboradores}

RGM Guimarães e S Rego participaram igualmente de todas as etapas da elaboração do artigo.

\section{Agradecimentos}

Os autores agradecem a Ma risa Palácios e Clary Sapiro pelos com en tá rios críti cos na primeira versão do manu scrito. 
Referências bibliográficas

Andrade LP 2003. Repúdio contra o Ato médico. Disponível em <http://www. nutricaoempauta.com.br/ novo/57/entrevista4.html>. Acessado em 21/Jun/ 2003.

Brasil 1991. Lei no 8.234, regulamentação da profissão de nutrição. DOU 1991 17/Set.

Brasil 2005. Câmara Federal. Disponível em <http:// www2.camara.gov.br/proposicoes $>$. Acessado em 6 de jan eiro de 2005.

Conselho Federal de Enfermagem (Cofen) 2005. Retumban tesvitórias judiciais. Dis pon ível em $<\mathrm{http}: / / \mathrm{www}$. portalcofen. gov.br $>$. Acessado em 21 de feverei ro de 2005.

Conselho Federal de Medicina (CFM) 2002. A medicina e os atos médicos: em defesa do direi to da população à assistência médica digna e de qualidade. Jornal do CFM Out: 7-8.

Conselho Federal de Medicina (CFM) 2003. Balanço político: em defesa do ato médico. Jornal do CFM nov./dez. ano XVIII no 146:6.

Conselho Federal de Medicina (CFM) 2004. A justiça federal do Dis tri to Fed eral pro íbe os en fermeiros de prescrever medicamentos e realizar diagnóstico. Disponível em <http://www.atomedico.org.br/decisoes. asp $>$. Ace s s ado em 8 de ago s to de 2004.

Conselho Federal de Medicina (CFM) 1999. O novo estatuto para os Conselhos de Medicina. Medicina Con s elho Federa 1. Jo rnal do CFM fev:24-25.

Conselho Nacional de Saúde (CNS) 1997. Regulamentação das profissões de Saúde, Resolução 218/97. Disponível em <http://www.saudeemmovimento. com.br/con teudos/con teudo_print.asp?cod_noticia $=193>$. Ace $s$ s adoem 8 de ago $s$ to de 2004 .

Conselho Regional de Medicina do Estado do Rio de Janeiro (Crem erj) 1998. Ato médico. Jornal do CREMERJ a br. ano XI n. 91:2.

Fink PJ 1997. What happened to the profession? Physician's News Digest. April. Disponível em <http:// www. physiciansneus.com/commentary/497 dv.html $>$. Ace s s adoem 23 de feverei ro de 2005.

G oode WJ 1969. The theoretical limits of profissionalization, pp. 277-278. In A Etzioni (ed.). The semi-professions and their organization. Free Press, New York.

Mach ado MH 1995. Sociologia das profissões: uma contribuição ao debate teóri co, pp. 13-33. In MH Mach ado (org.). Profissões de saúde: uma abord a gem sociológica. Fiocruz, Rio de Ja n ei ro.
Mach ado MH 1996. Os médicos e sua práticaprofissional: asmetamorfoses de uma prof issão. Tese de do utorado. Un ivers id adeEstadual do Rio de Jan ei ro.

Machado MH, Moysés N, Rego S \& Vieira ALS 1990. Saúde: qu em são os vilões da história? Boletim da Abem 22(2):2-4

Marinho MJMC 1986. Profissionalização e credenciamento: a politica das profissões. Senai/DN/DPEA, Rio de Jan eiro.

Milnitsky-Sapiro C 2000. Teorias em desenvolvimento sócio-moral: Piaget, Kohlberg e Turiel. Possíveis implicações para educação moral na educação médica. Revista Brasileira de Educação Médica 24(3):4-13.

Moretzsohn R 2004. Conselhos oposito res ao ato médico expõem sua opinião. Disponível em $<$ http://www. u n iversiabrasil.net $/$ materia.jsp?id $=5224>$. Acessado em 6 de ja n ei rode 2005.

Pittsburg State Un iversity 2003. Dis ponível em $<$ http:// www.pittstate.edu/artsc/diagn o sproced.htm $>$. Acessado em 6 de ja n ei ro de 2005.

Redepsi 2003. Luta pela derrubada do projeto de lei 25/ 2002, 2003. Tópico: Psicologia/Profissão. Disponível em <http://www.redepsi.com.br/portal/modules/ news $/$ print.php?storyid=453>. Acessado em 21 de junho de 2004.

Sa n tos PM 1995. Profissão médica no Brasil, pp. 97-118. In MH Machado (org.). Profissões de saúde: uma abordagem so ciológica. Fiocruz, Rio de Ja n ei ro.

Steinhilber J 2005. Con selhos oposito res ao ato médico expõem sua opinião. Dis ponível em $<\mathrm{http}$ ://www.universiabrasil.net $/ \mathrm{materia} . j s p ? i d=5224>$. Acessado em 6 de ja n ei ro de 2005.

Universia 2005. Conselhos oposito res ao ato médico expõem sua opinião. Dis ponível em $<\mathrm{http}$ ://www.universiabrasil.net $/ \mathrm{materia} . j s p ? i \mathrm{~d}=5224>$. Ace $s$ sado em 6 de ja n ei ro de 2005.

Viana T 2002. Proj eto de Lei do Sen ado, oo 25 (Substitutivo), de 2002. Disponível em <http://www.senado. gov.br/web/sen ador/tia ovian/atuacao/2002/2002eme ndapls25-substitutivo.html>. Acessadb em 6 de ja$\mathrm{n}$ ei ro de 2005.

Wilensky HL 1964. The professionalizati on of everyone? Amer. J. Sociol. 70:137-158. 